\title{
KEGIATAN PENANAMAN MANGROVE SEBAGAI SALAH SATU UPAYA PELESTARIAN EKOSISTEM PESISIR DI DUSUN CEMARA, KABUPATEN LOMBOK BARAT
}

\author{
Ayu Adhita Damayanti ${ }^{*}$, Ibadur Rahman, Nurliah, Sitti Hilyana \\ Program Studi Budidaya Perairan, Universitas Mataram \\ Jalan Pendidikan Nomor 37, Mataram 83125 \\ ${ }^{*}$ alamat korespondensi: adhitadama@gmail.com
}

\begin{abstract}
ABSTRAK
Hubungan timbal balik yang terjadi antara hutan mangrove dan kegiatan budidaya ikan selayaknya mengharuskan para pembudidaya ikan untuk tetap menjaga sinergi keduanya tidak terganggu. Namun demikian, tidak semua pembudidaya ikan mengetahui akan hal ini, sering kali pembukaan lahan budidaya dilakukan dengan mengurangi kepadatan vegetasi mangrove secara drastis, tanpa diikuti oleh proses penanaman kembali. Hal ini juga terjadi pada salah satu daerah hutan mangrove di Nusa Tenggara Barat, yaitu di Dusun Cemare Kabupaten Lombok Barat. Lahan budidaya dibuka tanpa adanya usaha untuk menjaga agar vegetasi mangrove tetap dalam proporsi yang seimbang. Mempertimbangkan begitu besarnya peran mangrove secara ekologi, yaitu sebagai penyuplai nutrisi dan penahan abrasi, menyebabkan harus segera dilakukan kegiatan penanaman kembali pada habitat mangrove yang telah rusak. Kegiatan ini akan dilaksanakan dengan melibatkan dosen, mahasiswa, dan kelompok pengelola setempat. Hasil pengabdian adalah telah tertanamnya bibit pohon mangrove di area terdampak, serta terjalinnya kerjasama dengan kelompok pengelola sumberdaya setempat untuk pemantauan pohon mangrove yang telah ditanam.
\end{abstract}

Kata kunci: penanaman mangrove, ekologi, pesisir, Dusun Cemare

\section{PENDAHULUAN}

Hutan Mangrove adalah salah satu vegetasi khas daerah pesisir pantai yang berkembang di daerah pasang surut, pantai berlumpur, teluk, dan pantai terlindung lainnya. Mangrove merupakan pelindung utama daerah pesisir dari serangan pasut yang kuat, dapat dimanfaatkan sebagai bahan makanan, kayu bakar maupun sebagai tanaman obat. Peran penting lainnya, mengingat lokasi tumbuh dan kembangnya hampir merata di daerah pesisir, maka hutan mangrove ini selalu berdampingan dengan kegiatan perikanan budidaya, sebagai penyangga ekologi atau memiliki 


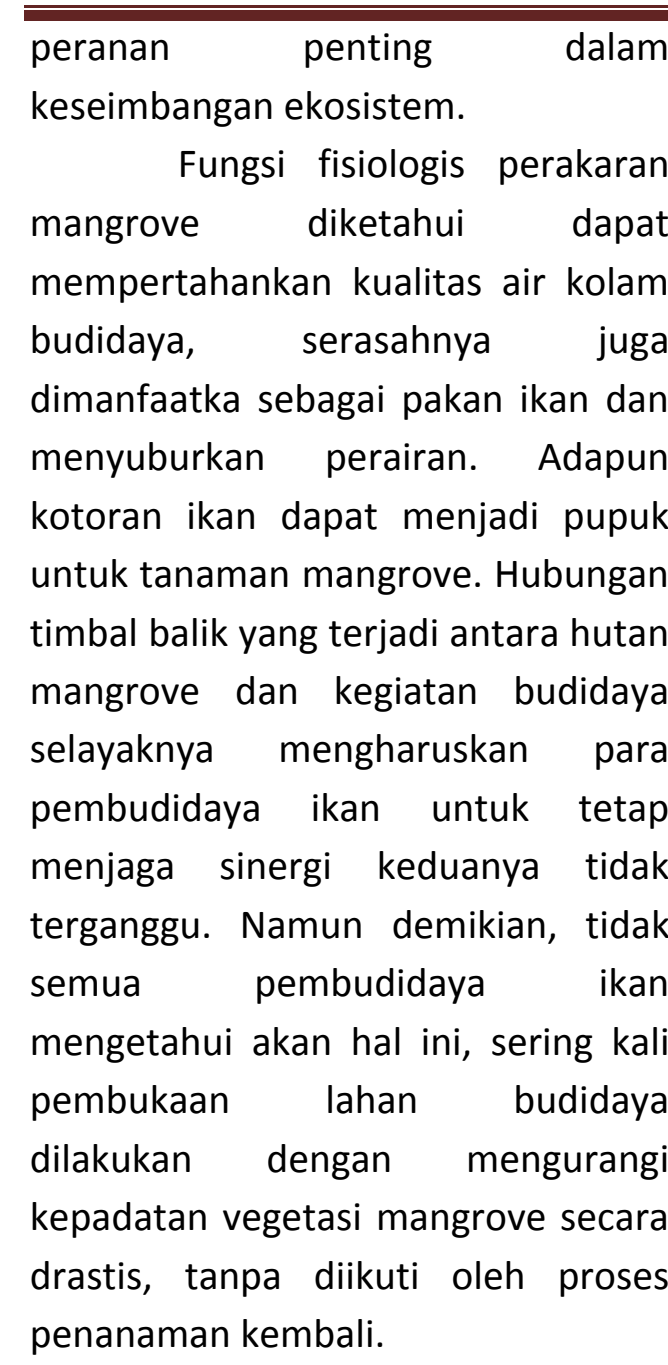

Menurut Soesanto dan Sudomo (1994) kerusakan ekosistem mangrove dapat disebabkan oleh berbagai hal, antara lain:

1. Kurang dipahaminya kegunaan ekosistem mangrove

2. Tekananekonomi masyarakat miskin yang bertempat tinggal atau sebagai bagian dari ekosistem mangrove

3. Karena pertimbangan ekonomi lebih dominan daripada pertimbangan lingkungan hidup.

Tekanan

ekosistem

mangrove yang berasal dari dalam, disebabkan karena pertumbuhan penduduk dan yang dari luar sistem karena reklamasi lahan dan eksploitasi mangrove yang makin meningkat telah menyebabkan perusakan menyeluruh atau kerusakan pada berbagai level yang berbeda. Terdapat ancaman yang semakin besar terhadap daerah yangbelum diganggu dan terjadi degradasi lebih lanjut pada daerah yang telah mengalami tekanan baik oleh sebab alami mapun perbuatan manusia (UNDP/UNESCO, 1984).

Hal ini juga terjadi pada salah satu daerah hutan mangrove di Nusa Tenggara Barat, yaitu di Desa Cemara Kabupaten Lombok Barat. Lahan budidaya dibuka tanpa adanya usaha untuk menjaga agar vegetasi mangrove tetap dalam proporsi yang seimbang. Mempertimbangkan begitu besarnya peran mangrove secara ekologi menyebabkan harus segera dilakukan kegiatan penanaman kembali. Pemulihan kembali ekosistem mangrove dapat menunjang kegiatan budidaya itu sendiri. Selain meningkatkan produktivitas budidaya, kolam budidaya dapat lebih terlindungi dari hempasan pasut karena telah dipagari oleh tanaman mangrove.

Rencana penanaman kembali ini tidak akan ada manfaatnya apabila tidak didukung oleh pemahaman yang menyeluruh dari masyarakat setempat terhadap arti penting ekosistem mangrove dan cara merawatnya. Oleh karena itu, 
kegiatan ini melibatkan masyarakat kelompok pengelola dan institusi Universitas Mataram yang terdiri dari dosen dan mahasiswa. Institusi Universitas Mataram, pada kegiatan ini akan dipresentasikan oleh Jurusan Perikanan dan Ilmu Kelautan, Program Studi Budidaya Perairan.

\section{METODE KEGIATAN}

Permasalahan yang menjadi sorotan adalah berkurangnya lahan mangrove akibat pembukaan lahan untuk kegiatan budidaya yang dikhawatirkan akan mengganggu keseimbangan ekologi. Melalui kegiatan pengabdian ini, Desa Cemara akan dibantu dengan sosialisasi untuk meningkatkan pemahaman dan kepedulian terhadap peran ekosistem mangrove pada lahan budidaya ikan, penanaman mangrove

Target luaran yang ingin dicapai dari kegiatan pengabdian ini adalah penambahan vegetasi mangrove sebagai penyangga ekologi daerah budidaya ikan di wilayah Desa Cemare.

Jenis kegiatan yang akan dilakukan adalah:

1. Survei lokasi

Survei lokasi penanaman pohon mangrove dilakukan untuk mengetahui daerah yang paling mendesak untuk ditanami mangrove.
2. Persiapan alat dan bahan serta materi teknis penanaman mangrove.

3. Kegiatan Sinergi dengan Kelompok Pengelola

Pemahaman mengenai arti penting mangrove sebagai penyangga ekologi sangat penting sehingga kepedulian dalam penjagaan kelestarian dapat ditingkatkan, sehingga sebelum penanaman akan dilakukan sinergi dengan kelompok pengelola terlebih dahulu.

4. Penanaman Mangrove

Panduan teknis singkat menanam mangrove akan diberikan oleh tim pengabdian, kemudian dilanjutkan dengan penanaman mangrove bersama

5. Evaluasi Kegiatan Kegiatan ini dilakukan untuk mengevaluasi kekurangan program dan merencanakan pengembangan program lanjutan.

\section{HASIL DAN PEMBAHASAN}

\section{Survei Lokasi}

Kegiatan

Pengabdian berlokasi di Dusun Cemara, Kabupaten Lombok Barat (Gambar 1). Desa ini merupakan desa pesisir yang memiliki kekayaan ekologi berupa hutan magrove dengan berbagai macam jenisnya. Jenis yang 
mendominasi adalah Rhizophora sp. dan Avicenia sp.

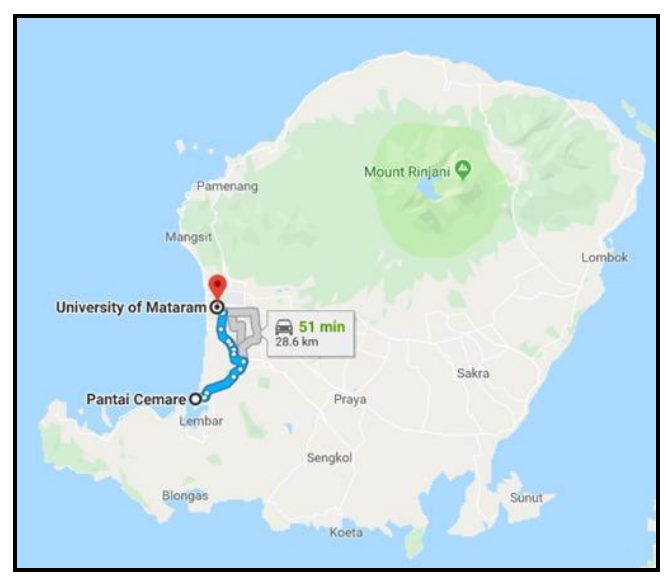

Gambar 1. Peta Lokasi Pengabdian

Hutan mangrove tumbuh disepanjang aliran sungai estuari. Daerah estuari merupakan ekosistem yang unik karena terdapat gradien salinitas akibat percampuran air laut dan air tawar. Daerah ini banyak dimanfaatkan oleh masyarakat lokal untuk membudidayakan ikan dengan membuka sebagian lahan mangrove. Akibatnya terdapat beberapa spot hutan mangrove yang dibiarkan gundul. Kekhawatiran muncul apabila hal ini terus dibiarkan. Keadaan ini dapat mengurangi fungsi ekologis hutan mangrove sebagai penghalang ombak besar dari lautan dan juga penyuplai nutrisi kolam budidaya.

Tim pengabdian pertama kali mendatangi Kepala Dusun Cemara untuk memperoleh gambaran jelas mengenai kondisi hutan mangrove dan persepsi masyarakat setempat mengenai hutan mangrove.
Kepala

Dusun

Cemara

menjelaskan bahwa sudah terdapat degradasi kerapatan tutupan hutan mangrove, terutama di daerah yang dekat pantai (teluk) dan aliran sungai. Berdasarkan informasi ini, tim kemudian bergerak untuk melihat lokasi yang dipaparkan. Kemudian diputuskan untuk melakukan penanaman di daerah yang dekat pantai karena dinilai lebih mendesak.

Selain itu, Kepala Dusun Cemara juga menjelaskan kurangnya pemahaman masyarakat setempat mengenai fungsi ekologis pohon mangrove. Kemampuan teknis menanam pohon mangrove juga tidak dimiliki oleh mereka. Oleh karena itu beliau menganggap perlu adanya sosialisasi di kesempatan yang akan datang.

Pada pertemuan ini juga dibicarakan mengenai kesepakatan waktu untuk penananaman mangrove. Penanaman mangrove disepakati akan dlaksanakan pada akhir minggu. Peserta adalah dosen, mahasiswa, dan perwakilan dari kelompok pengelola.

\section{Persiapan alat dan bahan serta materi teknis penanaman mangrove}

Tim Pengabdian Unram mempersiapan mangrove dari Jenis Rhizopora sp. sebanyak 150 pohon untuk ditanam. Jenis ini dipilih dengan pertimbangan keadaan lokasi 
dan jenis substrat. Lokasi penanaman berada di pinggir perairan dengan substrat berlumpur, sehingga membutuhkan jenis mangrove dengan perakaran dan batang yang kokoh dan dapat beradaptasi dengan kondisi berlumpur dan sering terendam air laut.

Alat pendukung yang digunakan adalah berupa bambu sebagai penyokong dan cangkul sebagai alat bantu penanaman.

Persiapan untuk materi teknis diperoleh dari pustaka yang disampaikan pada perkuliahan di kelas. Pustaka ini bersumber dari buku, artikel jurnal, serta artikel pada panduan praktis yang tersedia online.

\section{Kegiatan Sinergi dengan Kelompok Pengelola}

Kegiatan sinergi dengan kelompok pengelola setempat sangat penting dilakukan. Tim Pengabdian pada kegiatan kali ini mencoba pada membangun komunikasi dengan kelompok ini sebagai tahapan awal sebelum menyentuh masyarakat secara luas. Hal ini dilakukan karena kelompok ini dibentuk dengan salah satu tujuannya adalah menyampaikan ilmu pengelolaan sumberdaya kepada masyarakat Dusun Cemara. Sehingga diharapkan dengan memberikan masukan dan berdiskusi dengan kelompok ini mampu menguatkan kapasitas masyarakat sebagai pengelola mangrove pada akhirnya.

Kelompok pengelola sumberdaya Dusun Cemara yang bernama Kelompok Pengelola Sumberdaya Pesisir Mangrove Lestari (PSMPL) yang diketuai oleh Bapak Sahdan menyampaikan bahwa kelompok PSMPL akan siap mensupport semua kegiatan dan akan membantu bila ada kegiatan lanjutan dari pengabdian penanaman mangrove ini.

Kelompok PSMPL juga membantu Tim Pengabdian dalam mendapatkan bibit pohon mangrove di Dusun Cemara untuk ditanam kembali mengisi kekosongan di lokasi penanaman mangrove tersebut.

\section{Penanaman Mangrove}

Penanaman

mangrove dilakukan pada waktu yang disepakati. Peserta penanaman adalah dosen Tim Pengabdian dan dosen-dosen Program Studi Budidaya Perairan lainnya yang berkesempatan hadir beserta perwakilan dari kelompok PSMPL. Peserta penanaman mangrove dapat dilihat pada Gambar 2. 


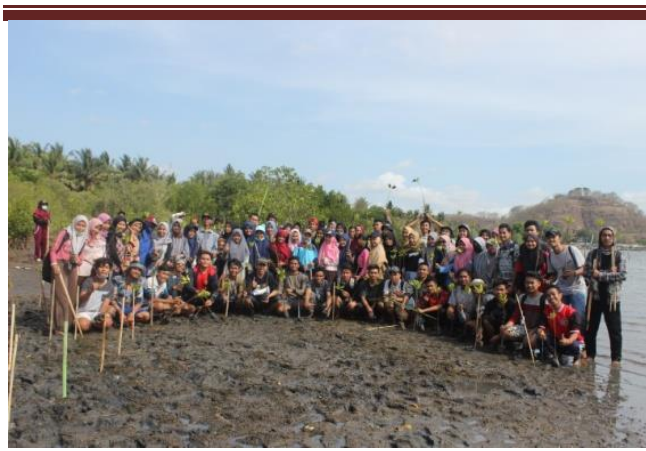

Gambar 2. Peserta Penanaman Mangrove

Sebelum mulai menanam, peserta diberikan pengarahan teknis mengenai cara penanaman mangrove. Berikut pedoman teknis sederhana yang dipaparkan oleh Priyono (2010):

1. Bibit mangrove ditanam satu persatu dan akar bibit dibuka dan jangan dibuang sembarangan.

3. Bibit mangrove ditanam langsung ke tanah dengan cara melubangi tanah dengan cepang, sehingga cukup dalam untuk menanam, dan akar bisa tertanam dengan baik

4. Batang bibit mangrove diikat ke bambu dengan menggunakan tali rafia

5. Batang ditimbun dengan tanah, tidak boleh terlalu ditekan, agar oksigen bisa tersirkulasi dengan baik.

Setelah pengarahan teknis, maka kegiatan penanaman dimulai (Gambar 3).
2. Polibag yang menutupi sedimen

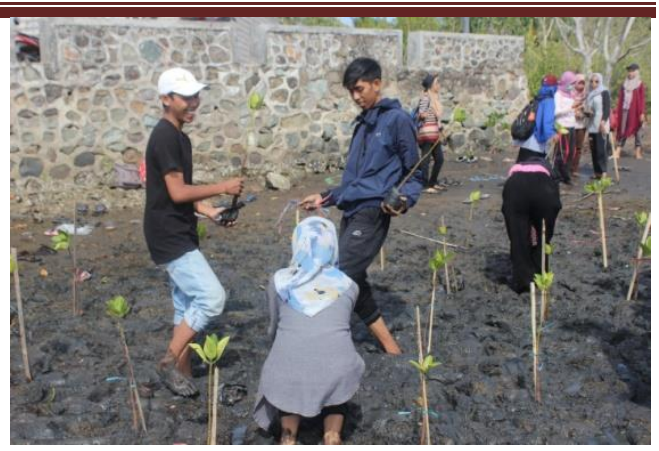

Gambar 3. Kegiatan Penanaman Mangrove

\section{Evaluasi Kegiatan}

Setelah selesai menanam mangrove, maka Tim Pengabdian melakukan tahap akhir kegiatan yaitu tahap evaluasi. Tahap evaluasi ditujukan untuk menilai kegiatan yang telah dilaksanakan dan merencanakan program-program lanjutan yang memungkinkan.

Hasil evaluasi kegiatan penanaman mangrove adalah masih diperlukannya banyak bibit untuk merehabilitasi lokasi. Tentu saja dengan pemilihan jenis yang sesuai dengan substrat yang ada. Hal lain yang perlu diperhatikan adalah bagaimana sistem pendampingan kepada masyarakat untuk pemeliharaan mangrove yang telah ditanam.

\section{KESIMPULAN DAN SARAN}

Kesimpulan dan saran yang
bisa diambil dari kegiatan
pengabdian ini antara lain:
1. Perlunya diadakan pemetaan detil
tentang tutupan hutan mangrove
Dusun Cemara secara


berkesinambungan sebagai bahan evaluasi

2. Masyarakat belum sepenuhnya sadar akan fungsi ekologi hutan mangrove sehingga kedepannya dapat diprogramkan untuk dilakukan sosialisasi mengenai hal tersebut.

3. Penanaman mangrove masih perlu dilakukan di Dusun Cemara

4. Perlu adanya kegiatan pendampingan pemeliharaan setelah dilakukan penanaman.

5. Peran Kelompok Pengelola Sumberdaya Pesisir Mangrove Lestari sangat baik sebagai mitra untuk pelaksanaan aksi teknis di lapang maupun penyebaran ilmu pengetahuan.

\section{UCAPAN TERIMAKASIH}

Tim Pengabdian masyarakat mengucapkan terima kasih kepada masyarakat Dusun Cemara, Kepala
Dusun Cemara, Kelompok Pengelola Sumberdaya Pesisir Mangrove Lestasi, Mahasiswa, dan seluruh dosen Prodi Budidaya Perairan Universitas Mataram atas dukungan dan kerja kerasnya hingga kegiatan ini selesai dilaksanakan.

\section{DAFTAR PUSTAKA}

Priyono, A. 2010. Panduan Praktis Teknik Rehabilitasi Mangrove di Kawasan Pesisir Indonesia. KeSEMat. Jawa Tengah.

Soesanto, S. S. dan M. Soedomo. 1994. Ekosistem Mangrove dan Pembangunan Lingkungan Hidup . Prosiding Seminar V Ekosistem Mangrove di Jember 3-6 Agustus 1994.

UNDP/UNESCO Regional Project Research and Training Pilot Programme on Mangrove Ecosystems in Asia and The Pacific. Bogor 8-9 Oktober 1984 